CLINICAL STUDY

\title{
Comparison of pharmacodynamic intrasubject variability of insulin lispro protamine suspension and insulin glargine in subjects with type 1 diabetes
}

\author{
S M Ocheltree, M Hompesch ${ }^{1}$, E T Wondmagegnehu, L Morrow ${ }^{1}, \mathrm{~K} \mathrm{Win}^{1}$ and S J Jacober \\ Lilly Research Laboratories, Diabetes Platform Team, Eli Lilly and Company, Lilly Corporate Center, Indianapolis, Indiana 46285, USA and \\ ${ }^{1}$ Profil Institute for Clinical Research, Inc., Chula Vista, California 91911, USA \\ (Correspondence should be addressed to S J Jacober; Email: sjacober@lilly.com)
}

\begin{abstract}
Objective: The objective of the study was to evaluate pharmacodynamic (PD) intrasubject variability of a single, s.c. dose of insulin lispro protamine suspension (ILPS) compared with insulin glargine in subjects with type 1 diabetes mellitus and additionally, to compare the intrasubject variability of pharmacokinetic parameters of both insulins.

Design: This was a single-center, investigator-blinded and subject-blinded, two-arm, parallel, randomized, four-period study. During the replicate visits, subjects received a single s.c. $0.6 \mathrm{U} / \mathrm{kg}$ dose of either ILPS or glargine, and underwent 24-h euglycemic glucose clamps.

Results: The intrasubject variabilities of the primary PD parameters, total amount of glucose infused $\left(G_{\text {tot }}\right)$ and maximum glucose infusion rate $\left(\mathrm{GIR} ; R_{\max }\right)$, were statistically significantly lower for ILPS when compared with glargine $(P<0.0001)$. Least-square (LS) mean estimates for $G_{\text {tot }}$ and $R_{\max }$ were $2512.7 \mathrm{mg} / \mathrm{kg}$ and $3.740 \mathrm{mg} / \mathrm{min}$ per $\mathrm{kg}$ respectively for ILPS, and $1291.9 \mathrm{mg} / \mathrm{kg}$ and $1.793 \mathrm{mg} / \mathrm{min}$ per $\mathrm{kg}$ respectively for glargine. The LS mean estimates for $G_{\mathrm{tot}}$ and $R_{\max }$ were statistically greater $(P=0.0010$ and $P<0.0001$ respectively) for ILPS compared with glargine, suggesting that ILPS had greater 24-h glucose-lowering activity. Glargine demonstrated a flatter GIR-time curve, and ILPS demonstrated a significantly shorter time of maximum GIR $\left(t R_{\max }\right)$ and earlier time to half-maximal GIR before $t R_{\max }$ and time to half-maximal GIR after $t R_{\max }$. ILPS administration resulted in significantly greater exposure compared with glargine (area under the baseline-corrected serum concentration versus time curve from time 0 to $24 \mathrm{~h}\left(\mathrm{AUC}_{0-24}\right): 77150 \mathrm{vs} 53111 \mathrm{pmol} \mathrm{min} / \mathrm{l}$; maximum serum insulin concentration $\left(C_{\max }\right)$ : 119 vs $68 \mathrm{pmol} / \mathrm{l}$; ILPS versus glargine respectively), but the intrasubject variabilities for AUC and $C_{\max }$ were comparable.

Conclusion: Although glargine demonstrated a flatter GIR-time profile, the lower PD intrasubject variability of ILPS may provide a more predictable response.
\end{abstract}

European Journal of Endocrinology 163 217-223

\section{Introduction}

Clinical experience indicates that daily s.c. administration of insulin often does not result in a reproducible metabolic effect even when injected at the same dose under comparable conditions (1). Especially, the high intrasubject variability of the glucose-lowering effect of basal insulins may be regarded as an obstacle to achieving optimal metabolic control (1). Cox et al. (2) noted that high glucose variability precedes episodes of severe hypoglycemia, suggesting that more stringent control of blood glucose (BG) levels in concert with less intrasubject variability of prandial and basal insulins may result in lowered risk of these episodes, particularly with respect to episodes of nocturnal hypoglycemia. Therefore, reducing pharmacodynamic (PD) intrasubject variability of s.c. administered basal insulins may have positive effects on short-term and long-term outcomes in regard to improved glycemic control with fewer episodes of hypoglycemia $(1,3)$.

Insulin lispro protamine suspension (ILPS; Humalog Basal (Europe), Humalog N (Japan), Eli Lilly and Company) is a basal insulin analog, which is formulated by cocrystallizing insulin lispro with protamine, thereby slowing the s.c. absorption of the otherwise rapid-acting insulin analog lispro. ILPS has been predominantly used as the basal insulin component of premixed biphasic formulations, which have had widespread use since 1998.

The primary objective of this study was to investigate and compare the variability of different PD parameters of ILPS with that of insulin glargine (glargine; Lantus, Sanofi-Aventis, Paris, France) by means of a euglycemic glucose clamp over the course of $24 \mathrm{~h}$ in subjects with 
type 1 diabetes mellitus (T1DM). To date, no direct comparative assessments of the PD properties of these two basal insulin formulations in subjects with T1DM have been published.

\section{Materials and methods \\ Study design and subjects}

This was an investigator-blinded, subject-blinded, parallel, randomized, four-period, euglycemic glucose clamp study conducted at a single center (Profil Institute for Clinical Research, Inc., Chula Vista, CA, USA). The study was approved by an ethical review board, and performed in accordance with the Declaration of Helsinki and Good Clinical Practice guidelines.

Eligible subjects had a diagnosis of T1DM (3) for $\geq 1$ year, a body mass index $\leq 35 \mathrm{~kg} / \mathrm{m}^{2}$, an $\mathrm{HbA} 1 \mathrm{c} \leq 12 \%$, a fasting serum C-peptide $\leq 0.5 \mathrm{ng} / \mathrm{ml}$, and no more than one episode of severe hypoglycemia within 6 months previous to study enrollment. Subjects were randomly assigned to receive either an s.c. injection of $0.6 \mathrm{U} / \mathrm{kg}$ of ILPS or $0.6 \mathrm{U} / \mathrm{kg}$ of glargine during a euglycemic glucose clamp on four occasions with each study visit separated by 5-21 days.

\section{Sample size calculation}

The minimal clinically observed PD intrasubject variability of any insulin is $\sim 30 \%(1,4)$. For this study, the required sample size needed was 33 patients per arm in order to have $\sim 90 \%$ power to demonstrate noninferiority of PD intrasubject variability of ILPS compared with glargine, within a margin of $30 \%$ and $\alpha=0.1$.

\section{Preparatory procedures for glucose clamp procedure}

Insulin glargine was last administered at least $48 \mathrm{~h}$ before each glucose clamp, and subjects were converted to neutral protamine Hagedorn (NPH) insulin according to dosing instructions provided by the investigator. $\mathrm{NPH}$, detemir, or premixed insulin formulations were last administered before $2400 \mathrm{~h}$ the day before each glucose clamp. Short-acting insulin analogs or rapidacting insulin analogs were not allowed after dinner the day before each glucose clamp.

\section{Glucose clamp procedure}

Subjects were admitted to the clinical research unit on the morning of each glucose clamp, provided they did not meet any of the following visit exclusion criteria: strenuous exercise within the $48 \mathrm{~h}$ prior to the visit, alcohol consumption within $24 \mathrm{~h}$ prior to the visit, clinically relevant hypoglycemic episodes within $24 \mathrm{~h}$ prior to the visit, any significant acute metabolic abnormalities, or improper discontinuation of insulins as described above.

Subjects underwent automated euglycemic glucose clamp procedures (Biostator (glucose-controlled glucose infusion system); Life Science Instruments, Elkhart, IN, USA; $(5,6))$ at each of the four clamp visits. Subjects fasted for at least $8 \mathrm{~h}$ before and for the entire duration of each clamp procedure.

An i.v. regular human insulin infusion (Humulin $\mathrm{R}$ (Eli Lilly and Company) at a rate of at least $0.15 \mathrm{mU} / \mathrm{kg}$ per min) was started at least $4 \mathrm{~h}$ before s.c. injection of the study insulin to achieve a target BG level of $5 \mathrm{mmol} / \mathrm{l}$ $(90 \mathrm{mg} / \mathrm{dl})$, and discontinued $\sim 15 \mathrm{~min}$ prior to study insulin administration. The study treatment (dosage based on that day's weight) was administered s.c. into the thigh with a conventional needle and syringe by qualified, blinded research staff.

Following the injection of the study insulin, the target BG concentration was maintained by the Biostator, which automatically calculated and adjusted the i.v. glucose infusion rate (GIR; via variable infusion of $20 \%$ dextrose). The GIR necessary to keep the BG stable at the target level was recorded every minute for $24 \mathrm{~h}$. Glucose clamps were stopped earlier if $\mathrm{BG}>11.1 \mathrm{mmol} / \mathrm{l}$ $(200 \mathrm{mg} / \mathrm{dl})$, and no glucose had been infused for at least $30 \mathrm{~min}$, provided the glucose clamp had lasted at least $8 \mathrm{~h}$.

\section{Laboratory methods}

Serum concentrations of nonantibody-bound (polyethylene glycol-treated) immunoreactive insulin (IRI) after administration of ILPS or glargine were determined using validated, nonspecific RIA methods ((7); Millipore BioPharma Services Laboratory, St Charles, MO, USA). Methods were individually validated for quantification using a guinea pig anti-insulin antiserum that was relatively nonspecific, crossreacting equally with glargine and ILPS as well as with native insulin. Thus, the serum IRI data represent the total of both endogenously administered and exogenously administered insulin.

\section{Pharmacodynamic analysis}

PD assessments were based upon the changes in GIR over time required to maintain $\mathrm{BG}$ at the target level. PD analyses were conducted on those subjects who had completed at least one glucose clamp procedure and had an evaluable GIR versus time profile.

A LOESS-smoothing function (smoothing parameter of 0.2) was applied to all individual GIR versus time profiles using SPlus (Version 6.2; Insightful Corp., Seattle, WA, USA). The fitted data for each subject were used to calculate the maximum GIR $\left(R_{\max }\right)$, the time of maximum GIR ( $\left.t R_{\max }\right)$, time to half-maximal GIR before $t R_{\max }$ (early $50 \% t R_{\max }$ ), time to halfmaximal GIR after $t R_{\max }$ (late $50 \% t R_{\max }$ ), and the total 
amount of glucose infused $\left(G_{\text {tot }}\right)$ over the duration of the clamp procedure.

Mean LOESS fits of GIR, BG concentration, and pre-dose insulin infusion rate profiles were generated using GIR data from all subjects in each treatment group and fitted simultaneously for graphical presentation, but were not used for the estimation of the PD parameters evaluated.

\section{Pharmacokinetic analysis}

Baseline endogenous serum insulin concentrations were assumed to be constant throughout the treatment, and were subtracted from the total serum insulin concentration measured to more accurately estimate the pharmacokinetics (PK) of ILPS and glargine. The individual serum insulin concentration at time point zero was used for calculating the individual subject baseline-subtracted values, which were analyzed by conventional noncompartmental PK analysis using WinNonlin Enterprise version 5.0.1 (Pharsight; Mountain View, CA, USA). Baseline values that were below the quantifiable limit (BQL) of the assay were assigned a value of BQL/2, and post-dose BQL and negative values were treated as missing data. Actual sampling times in individual subjects were used in the analysis.

PK parameters determined from baseline-subtracted concentration-time data included the following: area under the serum insulin concentration curve from time 0 to $24 \mathrm{~h}$ and from time 0 to $\infty\left(\mathrm{AUC}_{0-24}\right.$ and $\mathrm{AUC}_{0-\infty}$ respectively), the maximum serum insulin concentration $\left(C_{\text {max }}\right)$, and the time to maximum serum insulin concentration $\left(t_{\text {max }}\right)$. The AUC values were calculated by the linear/log trapezoidal method. PK parameters from all subjects completing at least one glucose clamp procedure in the assigned treatment sequence were calculated and included in the statistical analysis.

\section{Safety assessments}

Safety was assessed throughout the study by adverse events (AEs) and concomitant medication monitoring, physical examinations, clinical laboratory tests, electrocardiograms, and vital sign measurements.

\section{Statistical analysis}

Pharmacodynamic analysis Log transformation of $G_{\text {tot }}$ and $R_{\max }$ was performed prior to the analyses. A mixed effects linear model was applied. The model included treatment and period as fixed effects, and subject as random effect. PD intrasubject variability for each treatment group was obtained from the variance components of the model.

Noninferiority and superiority of ILPS over glargine for $G_{\text {tot }}$ in terms of intrasubject variability were declared if the null hypotheses $\sigma^{2}$ ILPS $/ \sigma^{2}$ glargine $\geq 1.3$ and $\sigma^{2}$ ILPS $/ \sigma^{2}$ glargine $\geq 1$.0 were respectively rejected at $\alpha=0.1$. The intrasubject variability of each insulin was expressed using coefficient of variance (CV; computed from within-subject residual error obtained by the mixed effect linear model). Both tests were conducted using an F-test. Similar analyses were performed for $R_{\text {max }}$.

All glucodynamic time parameters, $t R_{\max }$, early $50 \%$ $t R_{\text {max }}$, and late $50 \% t R_{\text {max }}$, were analyzed using Wilcoxon's signed rank method.

Pharmacokinetic analysis For comparison between treatments, a mixed effect linear model similar to the one used to assess PD parameters was applied. Log transformation was performed prior to the analyses. From the model, least-squares mean estimates and $90 \%$ confidence interval (CI) for mean differences between ILPS and glargine were calculated. An exponential transformation was applied to provide the ratios of geometric means and the $90 \% \mathrm{CI}$ of the ratio. CV (intrasubject) were presented for AUC and $C_{\text {max }}$.

A nonparametric method was used to analyze $t_{\max }$. The estimated median difference using HodgesLehmann estimator associated with Wilcoxon's signed rank statistic and a distribution-free 90\% CI based on Wilcoxon's signed rank test were both calculated and reported.

\section{Results}

\section{Subject demographics and disposition}

A total of 83 subjects participated in this study, with 41 subjects receiving at least one dose of ILPS and 42 subjects receiving at least one dose of glargine. Demographics and subject characteristics were similar between the treatment groups (Table 1). Eleven subjects in the ILPS group and six subjects in the glargine group discontinued early. The most common reasons for early discontinuation were subject decision and loss to followup. Two subjects in each group discontinued due to AEs not related to study drug or procedure.

Table 1 Subject demographics.

\begin{tabular}{lll}
\hline $\begin{array}{l}\text { Demographic parameter } \\
\text { (mean } \pm \text { s.D. or frequency } \\
\text { (percentage) }\end{array}$ & ILPS $(n=41)$ & Glargine $(n=42)$ \\
\hline Age (years) & $34 \pm 11$ & $36 \pm 11$ \\
Number of females (\%) & $19(46.3)$ & $18(42.9)$ \\
Race/ethnicity (\%) & $34(82.9)$ & $32(76.2)$ \\
White & $1(2.4)$ & $2(4.8)$ \\
Black & $6(14.6)$ & $8(19.0)$ \\
Hispanic & $16.9 \pm 9.9$ & $16.7 \pm 9.3$ \\
Duration of diabetes (years) & $8.21 \pm 1.48$ & $8.44 \pm 1.43$ \\
HbA1c $(\%)$ & $0.065 \pm 0.077$ & $0.0729 \pm 0.084$ \\
Serum C-peptide (ng/ml) & $25.01 \pm 4.10$ & $25.25 \pm 3.54$ \\
BMI (kg/m $\left.{ }^{2}\right)$ &
\end{tabular}

BMI, body mass index; ILPS, insulin lispro protamine suspension. 


\section{Analysis populations}

All 83 subjects who received at least one dose of the study drug were evaluated for safety. Sixty-six subjects (30 subjects in the ILPS group and 36 subjects in the glargine group) completed all four treatments. Of the 83 subjects who received at least one dose of the study drug, a total of 134 clamps for ILPS and 153 clamps for glargine were completed. Intrasubject variability was computed using data from 72 subjects who completed at least two clamps; intrasubject variability was not analyzed for 11 subjects who discontinued after only one clamp.

\section{Pharmacodynamic results}

Figure $1 \mathrm{~A}-\mathrm{C}$ displays the LOESS fits of mean GIR, BG concentration, and insulin infusion rate versus time data for all subjects after receiving a $0.6 \mathrm{U} / \mathrm{kg}$ s.c. dose of ILPS or glargine. The intrasubject variability of PD parameters for ILPS was significantly lower $(P<0.0001$

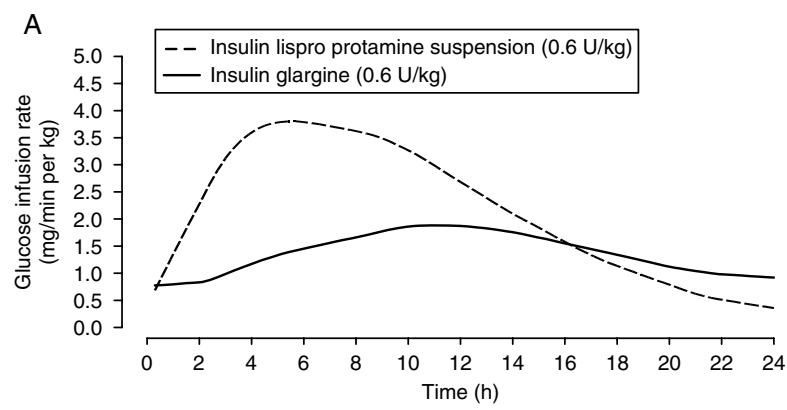

B

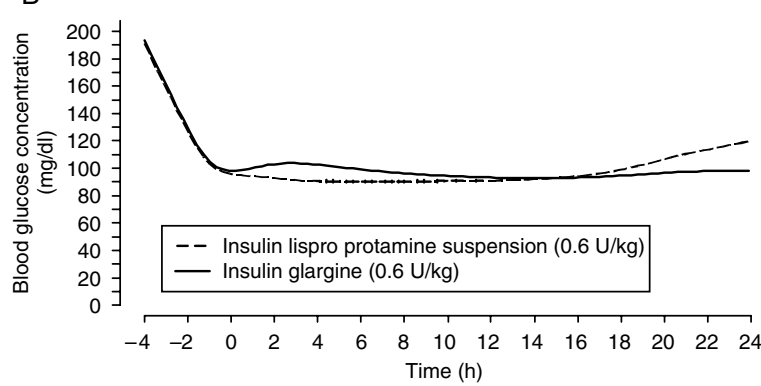

C

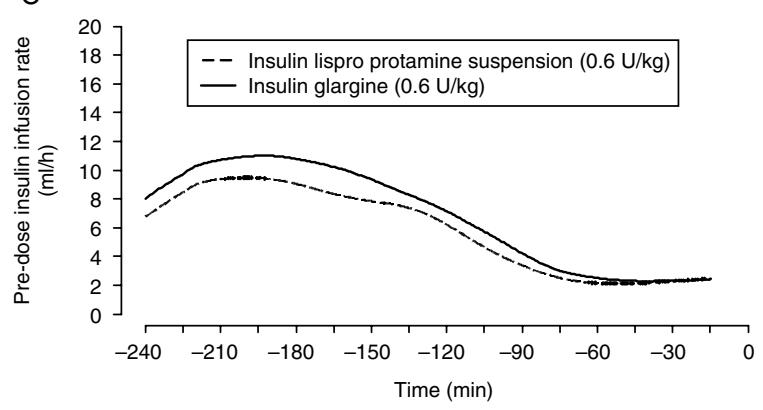

Figure 1 LOESS fits of glucose infusion rate versus time $(A)$, blood glucose concentration versus time $(B)$, and insulin infusion rates versus time $(\mathrm{C})$ for s.c. injection of insulin lispro protamine suspension or glargine at a dose of $0.6 \mathrm{U} / \mathrm{kg}$. for both $G_{\text {tot }}$ and $R_{\max }$ ) when compared with glargine (Table 2). A model-based statistical comparison of $G_{\text {tot }}$ and $R_{\max }$ demonstrated higher values for ILPS compared with glargine $(P=0.001$ and $P<0.0001$ respectively; Table 3 ), suggesting that ILPS has greater glucose-lowering activity over $24 \mathrm{~h}$ compared with that of glargine. ILPS also possessed earlier $t R_{\max }$ and earlier early and late $50 \% t R_{\max }(P<0.0001$ for all three parameters; Table 3), when compared with glargine at the same dose, suggesting an earlier onset and shorter duration of action in these patients with T1DM.

\section{Pharmacokinetic results}

Figure 2 shows the mean serum insulin versus time profiles of the two insulins. ILPS displayed a shorter median $t_{\max }$ compared with glargine $(P<0.0001$; Table 3). In addition, the exposure over $24 \mathrm{~h}\left(\mathrm{AUC}_{0-24}\right)$ was greater $(P=0.0113)$ for ILPS compared with glargine, although the estimated total exposure $\left(\mathrm{AUC}_{0-\infty}\right)$ was similar $(P=0.4313$; Table 3$)$. ILPS and glargine also demonstrated comparable intrasubject variability in exposure $\left(\mathrm{AUC}_{0-24}\right.$ and $\mathrm{AUC}_{0-\infty}$; Table 2). ILPS displayed higher maximum insulin levels $\left(C_{\max }, P<0.0001\right)$ with comparable intrasubject variability compared with glargine (Table 2).

\section{Safety}

Of the 83 subjects who received at least one dose of the study drug, 71 subjects reported a total of 283 AEs during the study. The most common AEs were nausea, vomiting, catheter site pain, and headaches. Most of these AEs were of mild or moderate severity. Two subjects, one from each group, had AEs that were considered related to study treatment, as determined by the investigator. Both events were mild headaches from which the subjects recovered. Approximately 1 month post treatment, one subject experienced an investigator-determined nontreatment-related and nonprocedural-related serious $\mathrm{AE}$ of severe diabetic ketoacidosis for which the subject was hospitalized and subsequently recovered.

\section{Discussion}

The rationale for conducting this study was to investigate and compare the variability of different PD parameters of ILPS with those of insulin glargine in subjects with T1DM by means of a euglycemic glucose clamp procedure. Few clinical trials $(1,8,9)$ have used 24-h euglycemic clamp techniques to determine PK and PD parameters of insulin glargine in subjects with T1DM; there are no comparable clinical trials for ILPS in this population. Although the s.c. injected doses of glargine varied from 0.3 to $0.6 \mathrm{U} / \mathrm{kg}$ in previous clamp studies $(1,8,9)$ and pre-clamp/clamp techniques 
Table 2 Statistical comparison of intrasubject variability for pharmacodynamic parameters and estimates of intrasubject variability for baseline-corrected pharmacokinetic parameters after s.c. injection of ILPS or insulin glargine (0.6 U/kg).

\begin{tabular}{|c|c|c|c|c|c|}
\hline \multirow[b]{2}{*}{ Parameter } & \multirow[b]{2}{*}{$\begin{array}{l}\text { Treatment } \\
\text { group }\end{array}$} & \multirow[b]{2}{*}{$\begin{array}{l}\text { Intrasubject } \\
\text { estimate CV\% }\end{array}$} & \multirow[b]{2}{*}{$\begin{array}{l}\text { Estimate of } \\
\text { intrasubject variance }\end{array}$} & \multicolumn{2}{|c|}{$\begin{array}{l}\text { Treatment comparisons } \\
\text { (ILPS versus insulin glargine) }\end{array}$} \\
\hline & & & & $\begin{array}{l}\text { Ratio of estimate } \\
\text { variance }^{\mathrm{a}}\end{array}$ & $\begin{array}{l}P \text { value for } \\
\text { superiority }\end{array}$ \\
\hline \multicolumn{6}{|l|}{ Pharmacodynamic } \\
\hline$G_{\text {tot }}(\mathrm{mg} / \mathrm{kg})$ & $\begin{array}{l}\text { ILPS } \\
\text { Glargine }\end{array}$ & $\begin{array}{l}48.4 \\
99.2\end{array}$ & $\begin{array}{l}0.21 \\
0.68\end{array}$ & 0.31 & $<0.0001$ \\
\hline$R_{\max }(\mathrm{mg} / \mathrm{min}$ per $\mathrm{kg})$ & $\begin{array}{l}\text { ILPS } \\
\text { Glargine }\end{array}$ & $\begin{array}{l}45.6 \\
75.2\end{array}$ & $\begin{array}{l}0.19 \\
0.45\end{array}$ & 0.42 & $<0.0001$ \\
\hline \multicolumn{6}{|l|}{ Pharmacokinetic } \\
\hline $\mathrm{AUC}_{(0-24)}(\mathrm{pmol} \mathrm{min} / \mathrm{l})$ & $\begin{array}{l}\text { ILPS } \\
\text { Glargine }\end{array}$ & $\begin{array}{l}86.5 \\
70.8\end{array}$ & & & \\
\hline $\mathrm{AUC}_{(0-\infty)}(\mathrm{pmol} \mathrm{min} / \mathrm{l})$ & $\begin{array}{l}\text { ILPS } \\
\text { Glargine }\end{array}$ & $\begin{array}{r}98.1 \\
118.1\end{array}$ & & & \\
\hline$C_{\max }(\mathrm{pmol} / \mathrm{l})$ & $\begin{array}{l}\text { ILPS } \\
\text { Glargine }\end{array}$ & $\begin{array}{l}69.1 \\
56.5\end{array}$ & & & \\
\hline
\end{tabular}

$\mathrm{AUC}_{(0-24)}$, area under the baseline-corrected serum concentration versus time curve from time 0 to $24 \mathrm{~h} ; \mathrm{AUC}(0-\infty)$, area under the baseline-corrected serum concentration versus time curve from time 0 to $\infty ; C_{\max }$, maximum serum insulin concentration; CV\%, percent coefficient of variation; ILPS, insulin lispro protamine suspension $0.6 \mathrm{U} / \mathrm{kg}$.

${ }^{\text {a }}$ Ratio of estimate variance = estimate of intrasubject variance for ILPS/estimate of intrasubject variance for glargine for that parameter.

and subject populations varied somewhat from the present study, the results for the PD and PK parameters determined were similar to those determined in this study, confirming the procedure and results presented here.

ILPS demonstrated less PD intrasubject variability compared to glargine in subjects with T1DM. This suggests that ILPS may provide more reproducible day-to-day metabolic control when used as a treatment in this population. Statistical analyses showed that $G_{\text {tot }}$ and $R_{\max }$ were higher for ILPS when compared with glargine at equivalent doses, suggesting that ILPS has greater 24-h glucose-lowering activity compared with that of glargine in patients with T1DM and T2DM (10); however, this difference may not be as great at steadystate conditions following repeated administration of the insulins. ILPS also demonstrated a significantly earlier onset of action with shorter $t R_{\max }$, early $50 \%$ $t R_{\text {max }}$, and late $50 \% t R_{\text {max }}$, suggesting that ILPS achieved maximum PD activity earlier. This suggests that glargine demonstrated a flatter profile and potentially a longer duration of action at an equivalent dose. However, ILPS and glargine had similar durations of action in a study by Hompesch et al. (10), in which subjects with type 2 diabetes were given a dose of $0.8 \mathrm{U} / \mathrm{kg}$ and studied over $24 \mathrm{~h}$. Although ILPS demonstrated less intrasubject variability than glargine in the T1DM cohort studied, this potential benefit may be offset by an earlier and greater glucoselowering activity.

No previous study has measured intrasubject variability of PD parameters for ILPS. Few studies have determined the PD intrasubject variability of glargine $(1,11,12)$, and only one study has made this determination using subjects with T1DM (1). Similar to the results seen in this study, Heise et al. (1) found high $G_{\text {tot }}$ and $R_{\max }$ intrasubject variabilities for glargine. However, the present study reports $G_{\text {tot }}$ and $R_{\max }$ intrasubject variabilities of 99 and $75 \%$ compared with 48 and $36 \%$ respectively, reported by Heise et al. While the euglycemic clamp methods and the statistical method used to compute the intrasubject variability are similar between the Heise and the present study, with each employing the Biostator and similar overall clamp techniques including the use of four replicate clamps per subject, there were a number of differences which may have led in part or in total to the disparity seen here. Differences in technique between sites and in the subject populations in different countries may have played roles. For example, in the Heise study, the BG level targeted for clamping was $5.5 \mathrm{mmol} / \mathrm{l}$ compared with $5.0 \mathrm{mmol} / \mathrm{l}$ in this study. Glargine group size also varied, with 16 subjects in the Heise study compared with 42 subjects in the present study. In terms of population demographics, the percentage of female subjects differed, with $56 \%$ in the Heise study compared with $43 \%$ in our study. Notably, the mean HbA1c levels of subjects enrolled in the Heise study (1) were $7.4 \pm 1.2 \%$ compared with $8.3 \pm 1.4 \%$ for subjects enrolled in our study, indicating that the Heise et al. (1) study may have had subjects with better long-term BG control. Lastly, the glargine dose was lower in the Heise study $(0.4 \mathrm{U} / \mathrm{kg})$ compared with this study $(0.6 \mathrm{U} / \mathrm{kg})$.

The statistical comparison of PD parameters, showing greater $G_{\text {tot }}$ and $R_{\max }$ for ILPS compared with glargine, was consistent with the model-based statistical comparison of $\mathrm{PK}$ parameters, which demonstrated greater $\mathrm{AUC}_{0-24}$ and $C_{\max }$ for ILPS compared with glargine. Although a difference in intrasubject variability of $G_{\text {tot }}$ and $R_{\max }$ was demonstrated between the 
Table 3 Statistical summary of serum pharmacodynamic and baseline-corrected pharmacokinetic parameters after s.c. injection of insulin lispro protamine suspension (ILPS) or insulin glargine $(0.6 \mathrm{U} / \mathrm{kg})$.

\begin{tabular}{|c|c|c|c|c|}
\hline & \multirow[b]{2}{*}{ Treatment group } & \multirow[b]{2}{*}{ Geometric LS means } & \multicolumn{2}{|c|}{ Treatment comparisons (ILPS versus insulin glargine) } \\
\hline & & & Ratio $(90 \% \mathrm{Cl})^{\mathrm{a}}$ & $P$ value \\
\hline$G_{\text {tot }}(\mathrm{mg} / \mathrm{kg})$ & $\begin{array}{l}\text { ILPS } \\
\text { Glargine }\end{array}$ & $\begin{array}{l}2512.7 \\
1291.9\end{array}$ & $1.95(1.41,2.69)$ & 0.0010 \\
\hline$R_{\max }(\mathrm{mg} / \mathrm{min}$ per $\mathrm{kg})$ & $\begin{array}{l}\text { ILPS } \\
\text { Glargine }\end{array}$ & $\begin{array}{l}3.740 \\
1.793\end{array}$ & $2.09(1.61,2.66)$ & $<0.0001$ \\
\hline $\mathrm{AUC}_{(0-24)}(\mathrm{pmol} \mathrm{min} / \mathrm{l})$ & $\begin{array}{l}\text { ILPS } \\
\text { Glargine }\end{array}$ & $\begin{array}{l}77150.4 \\
53110.7\end{array}$ & $1.45(1.15,1.84)$ & 0.0113 \\
\hline $\mathrm{AUC}_{(0-\infty)}(\mathrm{pmol} \mathrm{min} / \mathrm{l})$ & $\begin{array}{l}\text { ILPS } \\
\text { Glargine }\end{array}$ & $\begin{array}{l}94479.5 \\
84887.1\end{array}$ & $1.11(0.89,1.40)$ & 0.4313 \\
\hline \multirow[t]{3}{*}{$C_{\max }(\mathrm{pmol} / \mathrm{l})$} & $\begin{array}{l}\text { ILPS } \\
\text { Glargine }\end{array}$ & $\begin{array}{l}119.2 \\
68.0\end{array}$ & $1.75(1.42,2.16)$ & $<0.0001$ \\
\hline & & & \multicolumn{2}{|c|}{ Treatment comparisons (ILPS versus insulin glargine) } \\
\hline & & Median & $\begin{array}{l}\text { Median pairwise difference } \\
(90 \% \mathrm{Cl})\end{array}$ & $P$ value \\
\hline$t R_{\max }(\mathrm{h})$ & $\begin{array}{l}\text { ILPS } \\
\text { Glargine }\end{array}$ & $\begin{array}{l}6.5 \\
11.6\end{array}$ & $-4.2(-5.0,-3.3)$ & $<0.0001$ \\
\hline Early $50 \% t R_{\max }(\mathrm{h})$ & $\begin{array}{l}\text { ILPS } \\
\text { Glargine }\end{array}$ & $\begin{array}{l}2.0 \\
4.5\end{array}$ & $-2.4(-2.9,-1.9)$ & $<0.0001$ \\
\hline Late $50 \% t R_{\max }(\mathrm{h})$ & $\begin{array}{l}\text { ILPS } \\
\text { Glargine }\end{array}$ & $\begin{array}{l}14.3 \\
17.2\end{array}$ & $-2.2(-3.3,-1.3)$ & $<0.0001$ \\
\hline$t_{\max }(\mathrm{h})$ & $\begin{array}{l}\text { ILPS } \\
\text { Glargine }\end{array}$ & $\begin{array}{l}4.0 \\
9.0\end{array}$ & $-5.0(-6.0,-3.0)$ & $<0.0001$ \\
\hline
\end{tabular}

$\mathrm{AUC}_{(0-24)}$, area under the baseline-corrected serum insulin concentration versus time curve from time 0 to $24 \mathrm{~h} ; \mathrm{AUC}(0-\infty)$, area under the baseline-corrected serum insulin concentration versus time curve from time 0 to $\infty ; \mathrm{Cl}$, confidence interval; $C_{\text {max }}$, maximum serum insulin concentration; early $50 \% t R_{\text {max }}$, time to reach $50 \%$ of maximum GIR before $R_{\max }$; GIR, glucose infusion rate; $G_{\text {tot }}$, total amount of glucose infused; late $50 \% t R_{\text {max }}$, time to reach $50 \%$ of maximum GIR after $R_{\max }$; ILPS, insulin lispro protamine suspension; LS, least squares; $R_{\max }$, maximum GIR; $t_{\max }$, time to reach $C_{\max } ; R_{\max }$, sampling time of $R_{\max }$.

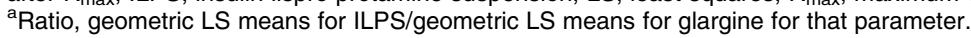

two insulins, the intrasubject variability for both $C_{\max }$ and exposure (AUC) was comparable between ILPS and glargine. This may be related to the variability of the insulin assay used in this study, which does not discriminate between glargine, ILPS, and other insulins, or may be due to the PK results, but not due to the PD results, being baseline corrected. However, the observed GIR versus time curves for ILPS and glargine are consistent with their respective serum insulin

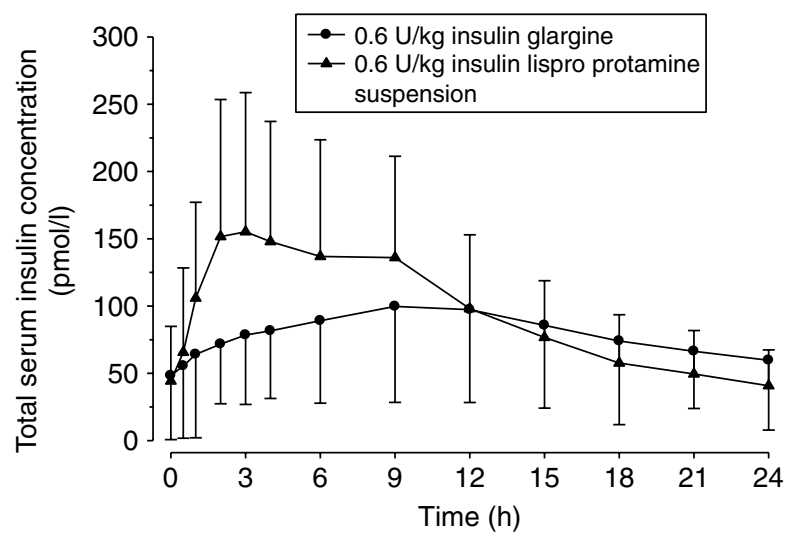

Figure 2 Mean serum insulin concentration ( \pm 1 s.D.) versus time for s.c. injection of insulin lispro protamine suspension or glargine $(0.6 \mathrm{U} / \mathrm{kg})$. concentration versus time profiles (Figs 1 and 2), illustrating the concordance between the PK and PD profiles observed for each insulin.

In summary, ILPS demonstrated a more rapid onset of action, greater glucose-lowering activity, and greater exposure than that of glargine after a single equivalent dose, although glargine shows a flatter GIR-time profile. The lower PD intrasubject variability of ILPS may provide a more predictable metabolic response and may offset the potential benefit of the flatter profile of glargine.

\section{Declaration of interest}

The authors declare that there is no conflict of interest that could be perceived as prejudicing the impartiality of the research reported.

\section{Funding}

S M Ocheltree, E T Wondmagegnehu, and S J Jacober are employees and shareholders of Eli Lilly and Company; M Hompesch, L A Morrow, and K Win are employees of Profil Institute for Clinical Research, which was sponsored by Eli Lilly and Company to conduct this trial.

\section{Acknowledgements}

The authors wish to thank Lutz Heinemann for critical review of the manuscript and Kathleen Kaysinger for assistance with writing the manuscript. 


\section{References}

1 Heise T, Nosek L, Rønn BB, Endahl L, Heinemann L, Kapitza C \& Draeger E. Lower within-subject variability of insulin detemir in comparison to NPH insulin and insulin glargine in people with type 1 diabetes. Diabetes 200453 1614-1620.

2 Cox DJ, Gonder-Frederick L, Ritterband L, Clarke W \& Kovatchev BP. Prediction of severe hypoglycemia. Diabetes Care 200730 1370-1373.

3 Heise T \& Pieber TR. Towards peakless, reproducible and logacting insulins. An assessment of the basal analogues based on isoglycaemic clamp studies. Diabetes, Obesity and Metabolism 2007 9 648-659.

4 Binder $\mathrm{C}$, Lauritzen $\mathrm{T}$, Faber $\mathrm{O}$ \& Pramming $\mathrm{S}$. Insulin pharmacokinetics. Diabetes Care 19847 188-199.

5 DeFronzo RA, Tobin JD \& Andres R. Glucose clamp technique: a method for quantifying insulin secretion and resistance. American Journal of Physiology. Gastrointestinal and Liver Physiology 1979 237 E214-E223.

6 Heinemann L \& Anderson JH Jr. Measurement of insulin absorption and insulin action. Diabetes Technology and Therapeutics $20046698-718$.

7 Freeman MM, Tajkowski P, Sloan J, Bowsher RR, Kamerud JQ, Shaw H, Ellis B \& Vick AM. Development of a novel immunoassay for the determination of insulin glargine and its active metabolites in human serum. AAPS Journal $2008 \mathbf{1 0} 483$.

8 Lepore M, Pampanelli S, Fanelli C, Porcellati F, Bartocci L, Di Vincenzo A, Cordoni C, Costa E, Brunetti P \& Bolli GB. Pharmacokinetics and pharmacodynamics of subcutaneous injection of long-acting human insulin analog glargine, NPH insulin, and ultralente human insulin and continuous subcutaneous infusion of insulin lispro. Diabetes 200049 2142-2148.

9 Porcellati F, Rosetti P, Ricci NB, Pampanelli S, Torlone E, Campos SH, Andreoli AM, Bolli GB \& Fanelli CG. Pharmacokinetics and pharmacodynamics of the long-acting insulin analog glargine after one week of use as compared to its first administration in subjects with type 1 diabetes mellitus. Diabetes Care 200730 1261-1263.

10 Hompesch M, Ocheltree SM, Wondmagegnehu ET, Morrow LA, Kollmeier AP, Campaigne BN \& Jacober SJ. Pharmacokinetics and pharmacodynamics of insulin lispro protamine suspension compared with insulin glargine and insulin detemir in type 2 diabetes. Current Medical Research and Opinion 200925 2679-2687.

11 Scholtz HE, Pretorius SG, Wessels DH \& Becker RH. Pharmacokinetic and glucodynamic variability: assessment of insulin glargine, NPH insulin and insulin ultralente in healthy volunteers using a euglycaemic clamp technique. Diabetologia $2005 \mathbf{4 8}$ 1988-1995.

12 Klein O, Lynge J, Endahl L, Damholt B, Nosek L \& Heise T. Albumin-bound basal insulin analogues (insulin detemir and NN344): comparable time-action profiles but less variability than insulin glargine in type 2 diabetes. Diabetes, Obesity and Metabolism 20079 290-299.

Received 5 May 2010

Accepted 27 May 2010 